3. Unlike other known active phenolases the enzyme released from a broad-bean leaf extract by Teepol is adsorbed strongly on diethylaminoethylcellulose.

It is a pleasure to acknowledge the technical assistance of Elizabeth P. McAllan.

\section{REFERENCES}

Bonner, W. D., jun. (1957). Annu. Rev. Pl. Physiol. $8,427$.

Brown, F. C. \& Ward, D. N. (1958). J. biol. Chem. 233, 77.
Dawson, C. R. \& Magee, R. J. (1955). In Methods in Enzymology, vol. 2, p. 819. Ed. by Colowick, S. P. \& Kaplan, N. O. New York: Academic Press Inc.

Frieden, E. \& Ottesen, M. (1959). Biochim. biophys. Acta, 34, 248.

Kenten, R. H. (1957). Biochem. J. 67, 300.

Kenten, R. H. (1958). Biochem. J. 68, 244.

Kertesz, D. \& Zito, R. (1957). Nature, Lond., 179, 1017.

Lowry, O. H., Rosebrough, N. J., Farr, A. L. \& Randall, R. J. (1951). J. biol. Chem. 193, 265.

Malmström, G., Fähraeus, G. \& Mosbach, R. (1958). Biochim. biophys. Acta, 28, 652.

Peterson, E. \& Sober, H. A. (1956). J. Amer. chem. Soc. 80, 1260.

Biochem. J. (1961) 79, 516

\title{
An Enzyme from Rat Liver Catalysing Conjugations with Glutathione
}

\author{
By J. BOOTH, E. BOYLAND AND P. SIMS \\ Chester Beatty Research Institute, Institute of Cancer Research; Royal Cancer Hospitai, \\ Fulham Road, London, S.W. 3
}

(Received 1 November 1960)

Many compounds are excreted in urine and bile as mercapturic acids, which are thio ethers of acetylcysteine, and there has been considerable speculation on the source of the cysteine used for the biosynthesis of these compounds. Evidence that glutathione is involved was supplied by the work of Barnes, James \& Wood (1959), who found that the levels of glutathione in the liver decreased when mercapturic acid-forming compounds were administered to rats. Furthermore, when $p$ chlorobenzyl chloride was given to a rabbit, investigations with paper chromatography provided evidence for the presence of $S$-( $p$-chlorobenzyl)glutathione in the liver, and this compound could be converted into $S$-( $p$-chlorobenzyl)cysteine by liver slices and homogenates and by glutathionase (Bray, Franklin \& James, 1959a). The $N$-acetylation of some of the $S$-substituted cysteines to the corresponding mercapturic acids was demonstrated in vivo and in tissue preparations in vitro (Bray, Franklin \& James, 1959b).

It has been shown that rat-liver slices convert naphthalene into $S$-(1:2-dihydro-2-hydroxy-1-naphthyl)glutathione (Booth, Boyland \& Sims, 1960b) and 1:2-dihydronaphthalene into $S$-(2-hydroxy1:2:3:4 - tetrahydro - 1 - naphthyl)glutathione. This latter reaction could also be accomplished by ratliver microsomes in the presence of reduced triphosphopyridine nucleotide, oxygen and glutathione, and the amount of glutathione derivative formed was increased by the addition of the soluble fraction of rat liver (Booth, Boyland, Sato \& Sims, $1960 a$ ).

This paper describes the partial purification and some of the properties of the liver enzyme which catalysed the formation of glutathione derivatives from various compounds.

\section{EXPERIMENTAL}

Materials. Triphosphopyridine nucleotide (TPN) as the dihydrate of the sodium salt, reduced TPN $\left(\mathrm{TPNH}_{2}\right)$ as the sodium salt, diphosphopyridine nucleotide (DPN), reduced DPN $\left(\mathrm{DPNH}_{2}\right)$ as the disodium salt, glucose 6-phosphate as the disodium salt, flavin mononucleotide as the monosodium salt dihydrate, adenosine 5-triphosphate (ATP) as the disodium salt and glucose 6-phosphate dehydrogenase were obtained from Sigma Chemical Co. Pyrophosphate buffers were prepared from $\mathrm{K}_{4} \mathrm{P}_{2} \mathrm{O}_{7}$ and $\mathrm{Na}_{2} \mathrm{H}_{2} \mathrm{P}_{2} \mathrm{O}_{7}$ and phosphate buffer from $\mathrm{KH}_{2} \mathrm{PO}_{4}$ and $\mathrm{Na}_{2} \mathrm{HPO}_{4}$. Concentrations of the constituents of the reaction mixtures refer to the final concentrations at the beginning of the incubations.

S-(2-Chloro-4-nitrophenyl)-L-cysteine. This was prepared from 2-chloro-4-nitroaniline by the method of Parke \& Williams (1951), when it formed pale-yellow needles from aq. ethanol, m.p. 176-178 ${ }^{\circ}$ (decomp.) (Found: N, 10.15; Cl, 12.45. Calc. for $\mathrm{C}_{9} \mathrm{H}_{9} \mathrm{O}_{4} \mathrm{~N}_{2} \mathrm{ClS}: \mathrm{N}, 10 \cdot 1 ; \mathrm{Cl}, 12 \cdot 8 \%$ ). Bray et al. $(1959 b)$ report m.p. $182^{\circ}$ for this compound prepared by the method of Suter (1895). Acetylation of the compound with acetic anhydride in $2 \mathrm{~N}-\mathrm{NaOH}$ yielded $N$-acetyl-S-(2-chloro-4-nitrophenyl)-L-cysteine in cream needles from ethanol, m.p. $193^{\circ}$. Bray, James \& Thorpe (1957) report m.p. $192-194^{\circ}$ for this derivative. 
S-(2-Chloro-4-nitrophenyl)glutathione. This compound was prepared from glutathione (2 g.) and 2-chloro-4-nitroaniline $(1 \cdot 1 \mathrm{~g}$.$) by the method described for the preparation$ of 1-naphthylglutathione (Booth et al. 1960b). S-(2Chloro-4-nitrophenyl)glutathione (0.95 g.) separated from aq. $90 \%$ ethanol-ether as a pale-yellow powder, m.p. $214^{\circ}$ (decomp.) (Found: $\mathrm{N}, 12 \cdot 6 ; \mathrm{Cl}, 7 \cdot 8 ; \mathrm{S}, 6 \cdot 8 . \mathrm{C}_{16} \mathrm{H}_{19} \mathrm{O}_{8} \mathrm{~N}_{4} \mathrm{ClS}$ requires $\mathrm{N}, 12 \cdot 1 ; \mathrm{Cl}, 7 \cdot 7 ; \mathrm{S}, 6 \cdot 9 \%$ ). Like the corresponding cysteine derivative, the compound turned brown on exposure to daylight. When the compound was heated with $\mathrm{HBr}$ (sp.gr. 1.7) for $4 \mathrm{hr}$. and the products were examined on paper chromatograms (with solvent 1 , Table 2), compounds indistinguishable from $S$-(2-chloro-4-nitrophenyl)cysteine, glycine and glutamic acid were detected.

$N$-Acetyl-L-cysteine was prepared by the method of Pirie \& Hele (1933) and trans-1:2-dihydro-1:2-dihydroxynaphthalene and trans-9:10-dihydro-9:10-dihydroxyphenanthrene by reduction of the corresponding $o$-quinones with lithium aluminium hydride (Booth, Boyland \& Turner, 1950). trans-1:2-Dihydro-1:2-dihydroxyphenanthrene was isolated from the urine of a rabbit dosed with phenanthrene (Boyland \& Wolf, 1950).

A solution of oxidized glutathione (GSSG) was prepared by adding a small excess of $50 \mathrm{~mm}$-potassium ferricyanide to a solution of $50 \mathrm{~mm}-\mathrm{GSH}(10 \mathrm{ml}$.) and keeping the mixture at room temperature for $1 \mathrm{hr}$. The solution was adjusted to pH 4 with acetic acid and the GSSG absorbed on charcoal (400 mg.). The charcoal was filtered off and washed with water until the washings were free of potassium ferricyanide (no blue colour with $\mathrm{FeCl}_{2}$ ). The GSSG was eluted with $10 \mathrm{ml}$. of methanol-benzene-aq. $\mathrm{NH}_{3}$ (sp.gr. 0.88) (87:10:3, by vol.). The eluate was evaporated to dryness and the GSSG was dissolved in 0.1 M-pyrophosphate buffer, pH 8.0 (10 ml.).

Tissue preparations. The liver fraction soluble in phosphate buffer was prepared by homogenizing livers from

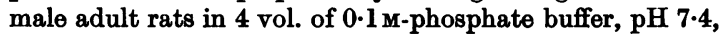
with a Potter \& Elvehjem (1936) type of homogenizer with a Teflon pestle. The homogenate was centrifuged for $30 \mathrm{~min}$. at $2000 \mathrm{~g}$ and the supernatant centrifuged for $1 \mathrm{hr}$. at $95000 \mathrm{~g}$ (centre of tube) in a Spinco model $\mathrm{L}$ preparative ultracentrifuge with rotor no. 40. The supernatant from the high-speed centrifuge was dialysed against water and the precipitate which separated was removed by centrifuging for $30 \mathrm{~min}$. at $2000 \mathrm{~g}$. The supernatant was adjusted to $\mathrm{pH} 7.4$ with $0.1 \mathrm{M}-\mathrm{K}_{4} \mathrm{P}_{2} \mathrm{O}_{7}$ and stored at $-2^{\circ}$. This preparation is referred to as the soluble liver fraction. Kidneys from male adult rats were homogenized in 4 vol. of $0.154 \mathrm{M}$ $\mathrm{NaCl}$ immediately before use. All operations were carried out at between $3^{\circ}$ and $8^{\circ}$.

Metabolism of 3:4-dichloronitrobenzene. This was investigated by incubating the following reaction mixtures at $37^{\circ}$ for $1 \mathrm{hr}$. (1) Soluble liver fraction (0.5 ml.), GSH, cysteine or acetylcysteine (5 $\mathrm{mM})$ and 3:4-dichloronitrobenzene ( $1 \mathrm{~mm}$, added in $0.1 \mathrm{ml}$. of ethanol) in a total volume of $6 \mathrm{ml}$. of $0.1 \mathrm{M}$-pyrophosphate buffer, $\mathrm{pH} 8.0$; (2) $S$-(2chloro-4-nitrophenyl)glutathione (1 mM) and kidney homogenate $(1 \mathrm{ml}$.) in a total volume of $6 \mathrm{ml}$. of $0.1 \mathrm{M}$-pyrophosphate buffer, pH 8.0; (3) $S$-(2-chloro-4-nitrophenyl)cysteine (1 mM) and slices of liver (approx. $5 \mathrm{~g}$. wet wt.) from adult rats in $50 \mathrm{ml}$. of Ringer phosphate solution, pH 7.4 (Umbreit, Burris \& Stauffer, 1949). At the end of the incubation period the reaction mixtures were studied by paper chromatography.
Paper chromatography. The reaction mixtures were added to acetic acid $(0.5 \mathrm{ml}$.) and centrifuged, and the supernatant was added to activated charcoal (50 mg.), shaken and again centrifuged. This supernatant was discarded and the charcoal was resuspended in water $(6 \mathrm{ml}$.) and filtered. The products were eluted from the charcoal with $10 \mathrm{ml}$. of methanol-benzene-aq. $\mathrm{NH}_{3}$ (sp.gr. 0.88) (87:10:3, by vol.) and the eluate was evaporated to a small volume and applied to Whatman no. 1 paper for chromatography. Descending chromatograms were developed for $18 \mathrm{hr}$. with one of the solvent systems listed in Table 2. The dried chromatograms were examined under u.v. light and then sprayed with (1) $20 \% \mathrm{Na}_{2} \mathrm{CO}_{3}$ (Bray et al. 1957) or (2) $0.1 \mathrm{M}-\mathrm{K}_{2} \mathrm{Cr}_{2} \mathrm{O}_{7}$-acetic acid (1:1), followed by $0.1 \mathrm{M}-\mathrm{AgNO}_{3}$ (Knight \& Young, 1958), or (3) diazotized $p$-nitroaniline $(0.02 \%$ in $0.1 \mathrm{~N}-\mathrm{HCl})$, followed by aq. $10 \%(\mathrm{w} / \mathrm{v}) \mathrm{Na}_{2} \mathrm{CO}_{3}$, or (4) diazotized $p$-nitroaniline $(0.02 \%$ in $4 \mathrm{~N}-\mathrm{HCl})$, after which the papers were heated at $70^{\circ}$ until colours appeared (about 5 min.) and then sprayed with aq. $10 \%(w / v)$ $\mathrm{Na}_{2} \mathrm{CO}_{3}$. Other papers were dipped in a solution of ninhydrin $(0.4 \%)$ in acetone, heated in an oven at $70^{\circ}$ for $5 \mathrm{~min}$. and then dipped in a solution of $\mathrm{Cu}\left(\mathrm{NO}_{3}\right)_{2}(0 \cdot 2 \%)$ in acetone.

Estimation of enzyme activity. The substrate chosen for the estimation of enzyme activity was 3:4-dichloronitrobenzene, because of the change in the ultraviolet-absorption spectrum which occurs when this compound is converted into $S$-(2-chloro-4-nitrophenyl)glutathione (Figs. 1 and 2). In obtaining the readings in Fig. 2, a cell containing all the constituents of the reaction mixture except 3:4-dichloronitrobenzene was used as the blank, so that the rate of increase of $E$ at $344 \mathrm{~m} \mu$ is a measure of the rate of formation of $S$-(2-chloro-4-nitrophenyl)glutathione. This increase was measured on a Unicam SP. 500 spectrophotometer with a Unicam SP. 570 constant-temperature-cell housing. The reaction mixtures contained GSH (5 mM), various concentrations of 3:4-dichloronitrobenzene (added in $0.1 \mathrm{ml}$. of ethanol) and enzyme in a total volume of $3.0 \mathrm{ml}$. of $0.1 \mathrm{M}$ pyrophosphate buffer, $\mathrm{pH} 8 \cdot 0$. The enzyme was diluted so that the rate of increase in $E$ was less than $0 \cdot 2 / \mathrm{min}$. The reactions were carried out at $37^{\circ}$, the constituents being brought to this temperature before the determination and the reaction was started by the addition of the enzyme solution to the cell. After stirring, readings at $344 \mathrm{~m} \mu$ were taken at 30 sec. intervals for $5.5 \mathrm{~min}$., beginning 30 sec. after mixing. Under these conditions the initial reaction rates were constant for at least $10 \mathrm{~min}$. and 1 unit of enzyme is defined as that amount which will form $1 \mu$ mole of S-(2-chloro-4-nitrophenyl)glutathione/min. Specific activity is expressed as units/mg. of protein. Protein was estimated by a modification of the biuret method (Fincham, 1954) or by the method of Warburg \& Christian (1941).

Location of the enzyme. To determine the intracellular location of the enzyme, a 1 in 10 homogenate of adult male rat liver in $0.25 \mathrm{M}$-sucrose was prepared as described for the phosphate-buffer homogenate. The sucrose homogenate was fractionated by the method of Schneider \& Hogeboom (1950), except that the microsome fraction was separated from the soluble fraction by centrifuging at $95000 \mathrm{~g}$ (centre of the tube) for $1 \mathrm{hr}$. in a Spinco model $\mathrm{L}$ preparative ultracentrifuge with rotor no. 40. The particulate fractions were suspended in 0.1 M-pyrophosphate buffer, $\mathrm{pH} 8.0$, in volume equivalent to those of the original homogenate and the fractions were diluted with this buffer for measurements of enzyme activity. 
To determine the distribution of the enzyme in the soluble fraction of various rat tissues, the tissues were

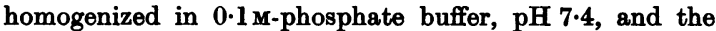
phosphate buffer-soluble fractions prepared as described for liver. Blood was added to an equal volume of water and after $10 \mathrm{~min}$. an equal volume of $0.1 \mathrm{M}$-phosphate buffer was added. The supernatant after centrifuging for $1 \mathrm{hr}$. at $95000 \mathrm{~g}$ was then used for measurements of enzyme activity.

Partial purification of the enzyme. Steps 1 and 2 are the homogenization of rat liver and the preparation of the soluble fraction as described above. Step 3. The undialysed soluble liver fraction was adjusted to $\mathrm{pH} 5 \cdot 2$ with acetic acid (approx. $0.55 \mathrm{ml} . / 100 \mathrm{ml}$.), centrifuged for $15 \mathrm{~min}$. at $2000 \mathrm{~g}$ and the ppt. discarded. The supernatant was dialysed against water for $\mathbf{1 8} \mathrm{hr}$., centrifuged as before and the ppt. again discarded. The supernatant was adjusted to pH 8.0 with $0.1 \mathrm{M}-\mathrm{K}_{4} \mathrm{P}_{2} \mathrm{O}_{7}$ and the centrifuging repeated. Step 4. To the supernatant from step $3,\left(\mathrm{NH}_{4}\right)_{2} \mathrm{SO}_{4}(47 \cdot 2 \mathrm{~g}$.

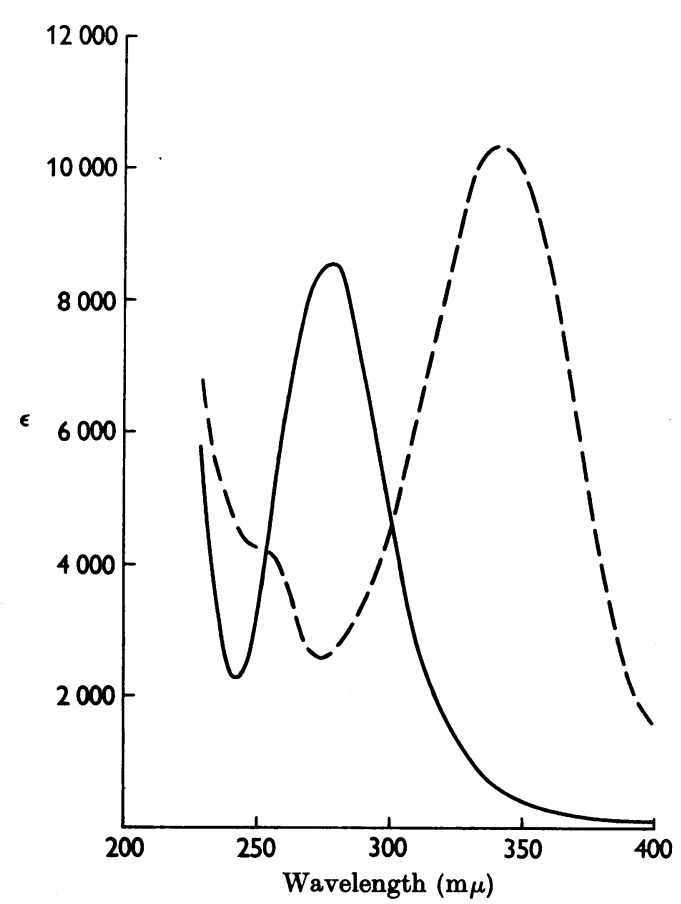

Fig. 1. Absorption spectra in 0.1 M-pyrophosphate buffer, pH 8.0: —, 3:4-dichloronitrobenzene; - . , S-(2-chloro-4nitrophenyl)glutathione.
$100 \mathrm{ml}$.) was added and, after $30 \mathrm{~min}$., the ppt. was removed by centrifuging and discarded. A small portion of the supernatant was dialysed against water and used for activity measurements. Step 5. The supernatant from step 4 was adjusted to $\mathrm{pH} 4.5$ with $5 \%$ acetic acid and centrifuged for $30 \mathrm{~min}$. at $2000 \mathrm{~g}$. The ppt., which contained the activity, was dissolved in $0.1 \mathrm{vol}$. of $0.1 \mathrm{M}$-pyrophosphate

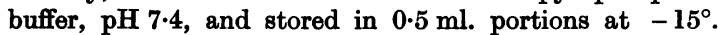
Immediately before use a portion was allowed to thaw at room temperature and was diluted 40 times with $0.1 \mathrm{M}$ pyrophosphate buffer, pH $8 \cdot 0$, so that when $0.25 \mathrm{ml}$. of this solution was present in $3 \mathrm{ml}$. of reaction mixture the total dilution factor was 480 and the protein concentration was $0.0117 \mathrm{mg} . / \mathrm{ml}$. This gave a change in $E$ at $344 \mathrm{~m} \mu$ of 0.15 to $0 \cdot 20 / \mathrm{min}$. under the optimum conditions. All operations were carried out at between $3^{\circ}$ and $8^{\circ}$. The partial purification of the enzyme by these steps is summarized in Table 1.

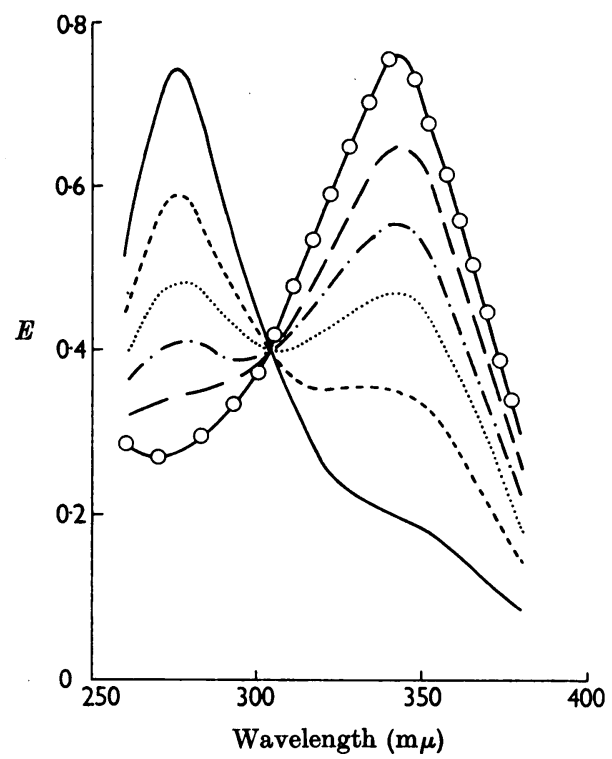

Fig. 2. Effect on ultraviolet absorption of incubating 3:4dichloronitrobenzene with GSH and enzyme. Reaction mixtures contain 3:4-dichloronitrobenzene $(0 \cdot 1 \mathrm{~mm})$, GSH (5 mM) and $0.25 \mathrm{ml}$. of enzyme solution in $3 \mathrm{ml}$. of $0.1 \mathrm{M}$ pyrophosphate buffer, pH 8.0. The readings for each curve occupied approx. 1 min. and were started at the following times (min.) after adding the enzyme solution,$- 1 ;--, 6$;

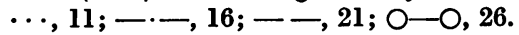

Table 1. Summary of the partial purification of the enzyme from a 1 in 5 homogenate of rat liver in 0.1 M-phosphate buffer, $\mathrm{pH} 7 \cdot 4$

Step

(1) Whole homogenate

(2) Soluble liver fraction

(3) Precipitation at $\mathrm{pH} 5 \cdot 2$ and dialysis

(4) $\left(\mathrm{NH}_{4}\right)_{2} \mathrm{SO}_{4}$ fractionation at $\mathrm{pH} 8 \cdot 0$

(5) $\left(\mathrm{NH}_{4}\right)_{2} \mathrm{SO}_{4}$ fractionation at $\mathrm{pH} 4.5$

$\begin{array}{ccc}\begin{array}{c}\text { Volume } \\ \text { (ml.) }\end{array} & \begin{array}{c}\text { Activity } \\ \text { (units/ml.) }\end{array} & \begin{array}{c}\text { Total } \\ \text { units }\end{array} \\ 360 & 21 & 7560 \\ 245 & 27 & 6615 \\ 270 & 19 & 5130 \\ 330 & 9 & 2970 \\ 33 & 90 & 2970\end{array}$

$10^{2} \times$ Specific activity $\begin{array}{ccc}\text { Protein } & \begin{array}{c}\text { (units/mg. } \\ \text { (mg./ml.) }\end{array} & \begin{array}{c}\text { Recovery } \\ \text { of protein) }\end{array}\end{array}$ $45 \cdot 1$ $26 \cdot 2$

$12 \cdot 1$ $1 \cdot 4$ $5 \cdot 6$
47

104

158

643

1607
100

87

68

39 


\section{Table 2. Paper chromatography of 3:4-dichloronitrobenzene metabolites}

Solvent systems: (1) butanol-acetic acid-water (12:3:5); (2) butanol-acetic acid-water (2:1:1). All metabolites showed dark absorption in u.v. light and gave a positive reaction with the $\mathrm{K}_{2} \mathrm{Cr}_{2} \mathrm{O}_{7}-\mathrm{AgNO}_{3}$ reagent.

Reaction mixture or reference compound

3:4-Dichloronitrobenzene, dialysed soluble liver fraction and GSH

$S$-(2-Chloro-4-nitrophenyl)glutathione

$S$-(2-Chloro-4-nitrophenyl)glutathione and kidney

homogenate

$S$-(2-Chloro-4-nitrophenyl)-L-cysteine

$S$-(2-Chloro-4-nitrophenyl)-L-cysteine and liver slices

$N$-Acetyl-S-(2-chloro-4-nitrophenyl)-L-cysteine

Solvent (1)
0.45
0.44
0.57
0.59
0.89
0.89

$R_{\boldsymbol{F}}$

Solvent (2)

0.62

0.61

$0 \cdot 67$

$0 \cdot 67$

$0 \cdot 86$

$0 \cdot 86$
Colour with ninhydrin and $\mathrm{Cu}\left(\mathrm{NO}_{3}\right)_{2}$

Rod

Red

Red

Red

Orange

Orange
Colour with $\mathrm{Na}_{2} \mathrm{CO}_{3}$

Yellow

Yellow

Yellow

Yellow

Pale yellow

Pale yellow
Identification of glutathione conjugates with various sub. strates. Reaction mixtures contained soluble liver fraction (2 ml.), GSH (5 mM) and 0.1 M-pyrophosphate buffer, $\mathrm{pH} 8.0$, in a final volume of $6 \mathrm{ml}$. The substrates were added in ethanol $(0.2 \mathrm{ml}$.) to give a final concn. of $1 \mathrm{~mm}$; some of the compounds were partially precipitated and with these the excess of substrate was allowed to remain in suspension. With the substrates iodobenzene, naphthalene, 1 chloronaphthalene and phenanthrene the following cofactors were also added: $\operatorname{DPNH}_{2}(0.2 \mathrm{mM})$, nicotinamide $(2 \mathrm{mM})$, TPN (0.2 mM), glucose 6-phosphate $(2 \mathrm{~mm})$, glucose 6phosphate dehydrogenase $(0.01 \%)$ and $1 \mathrm{ml}$. of microsome suspension prepared as described by Booth et al. (1960a). Two incubation flasks were used for each substrate, one containing $2 \mathrm{ml}$. of soluble liver fraction and the other either $2 \mathrm{ml}$. of soluble liver fraction which had been heated at $100^{\circ}$ for $5 \mathrm{~min}$. before the incubation or $2 \mathrm{ml}$. of buffer solution.

The mixtures were incubated at $37^{\circ}$ for times which varied between $2 \mathrm{~min}$. and $1 \mathrm{hr}$, according to the substrate, the same time being used for each pair of flasks containing the same substrate. The products were adsorbed on charcoal and eluted as described above, and the eluates were evaporated to dryness and methanol $(0.25 \mathrm{ml}$.) containing aq. $1 \% \mathrm{NH}_{3}$ (sp.gr. 0.88) was added to the residues. For each substrate the same volume of the methanol extract from the two experiments (boiled and fresh soluble liver fraction) was applied with micropipettes to chromatography paper for comparison. With some substrates only a small fraction of the methanol was used, to avoid overloading. The dried chromatograms were treated with the ninhydrin reagent followed by the $\mathrm{Cu}\left(\mathrm{NO}_{3}\right)_{2}$ solution. The spots were cut out, the coloured compounds eluted with $50 \%$ methanol and the extinctions measured at $510 \mathrm{~m} \mu$ on the Unicam SP. 500 spectrophotometer. A reaction mixture which contained soluble liver fraction and GSH but no substrate was treated in the same way for use as a blank.

In the experiments with naphthalene and phenanthrene, other paper chromatograms were treated with the diazotized $p$-nitroaniline reagents (3) and (4).

\section{RESULTS}

Metabolism of 3:4-dichloronitrobenzene. The conversion of 3:4-dichloronitrobenzene into $N$-acetyl$S$-(2-chloro-4-nitrophenyl)-L-cysteine (Bray et al.

\section{Table 3. Intracellular location of the enzyme}

Samples of the fractions of 1 in 10 rat-liver homogenate in $0.25 \mathrm{M}$-sucrose were incubated with GSH (5 mM) and 3:4-dichloronitrobenzene (1 mM) in $0.1 \mathrm{M}$-pyrophosphate buffer, pH 8.0 (total vol. $3 \mathrm{ml}$.).

Intracellular fraction
Whole homogenate
Nuclei
Mitochondria
Microsomes
Soluble fraction

Activity
(units/ml.)
$15 \cdot 8$
$0 \cdot 8$
$0 \cdot 8$
$0 \cdot 7$
$13 \cdot 0$

Activity (as \% of whole homogenate) 100 100 5 5 82

\section{Table 4. Distribution of the enzyme in the soluble fractions of rat tissues}

Reaction mixtures contained GSH (5 mM), 3:4-dichloronitrobenzene (1 $\mathrm{mM})$ and soluble liver fractions in $0.1 \mathrm{M}$ pyrophosphate buffer, pH 8.0 (total vol. $3 \mathrm{ml}$.).

$\begin{array}{lc}10^{2} \times \text { Specific } \\ \text { activity } \\ \text { (units } / \mathrm{mg} \text {. } \\ \text { Tissue } & \text { of protein) } \\ \text { Liver } & 96.2 \\ \text { Heart } & 2.9 \\ \text { Kidney } & 2.4 \\ \text { Lung } & 1.6 \\ \text { Spleen } & 0.5 \\ \text { Blood } & 0.1\end{array}$

1957) in three stages is demonstrated by the results in Table 2. The first reaction, which is catalysed by the soluble liver fraction, is the replacement of the para chlorine atom by GSH to form $S$-(2-chloro-4-nitrophenyl)glutathione. If GSH is replaced by cysteine or acetylcysteine in the reaction mixture no corresponding derivatives can be detected on the chromatograms. Kidney homogenate removes glycine and glutamic acid from $S$-(2-chloro-4-nitrophenyl)glutathione to form $S$ (2-chloro-4-nitrophenyl)-L-cysteine, which is then acetylated by liver slices to the mercapturic acid, $N$-acetyl-S-(2-chloro-4-nitrophenyl)-L-cysteine. 
Location of the enzyme. The estimations of enzyme activity in the intracellular fractions of a rat-liver homogenate in $0.25 \mathrm{M}$-sucrose shows that $82 \%$ of the activity is present in the soluble fraction (Table 3). The activities of the soluble fractions of various rat tissues are listed in Table 4, which shows that liver has between 30 and 200 times the activity of the other tissues investigated.

Some properties of the partially purified enzyme. The activity is completely destroyed by heating at $100^{\circ}$ for $5 \mathrm{~min}$. and is not affected by dialysis. The initial reaction rate under the conditions described is constant for at least $10 \mathrm{~min}$. and is directly proportional to enzyme concentration when this is adjusted to give a change in $E$ at $344 \mathrm{~m} \mu$ of 0.2 / min. or less. The $\mathrm{pH}$-activity curve (Fig. 3) shows a broad region of optimum activity between 7.5 and $9 \cdot 0$, but a rapid decrease on either side of these values. Replacement of pyrophosphate buffer by $\mathrm{Na}_{2} \mathrm{CO}_{3}-\mathrm{NaHCO}_{3}$ buffer, of the same molarity and $\mathrm{pH}$, at the $\mathrm{pH}$ of optimum activity had no effect on the reaction rate.

GSH was used throughout at a concentration of $5 \mathrm{~mm}$, and increasing this value produced no increase in enzyme activity. Although it could be demonstrated that a decrease in GSH concentration caused a decrease in activity, a quantitative

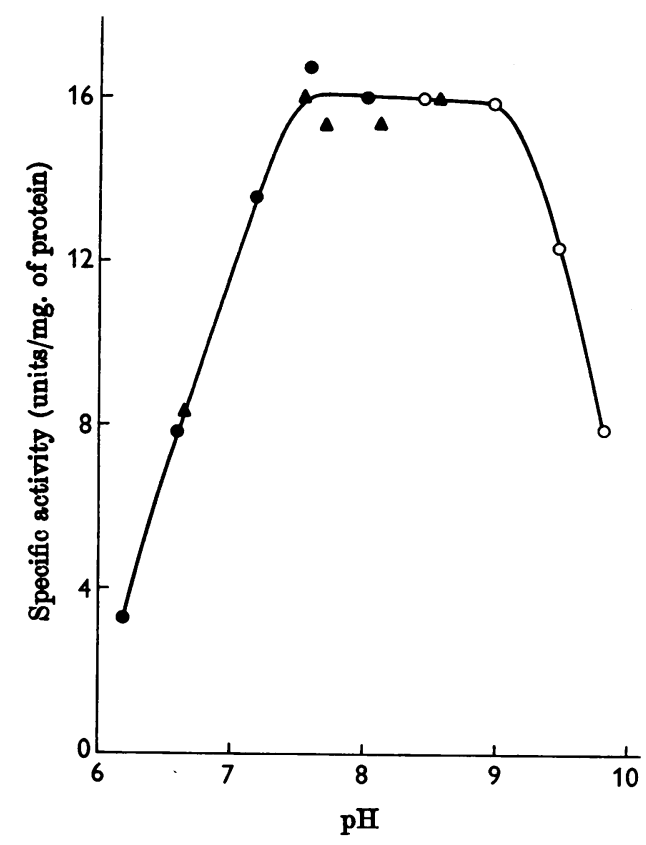

Fig. 3. pH-Activity curve. Reaction mixtures contain 3:4-dichloronitrobenzene (1 mM), GSH (5 mM) and $0.25 \mathrm{ml}$. of enzyme solution in $3 \mathrm{ml}$. of $0.1 \mathrm{~m}$-buffer solution, the final pH values being shown. 0, Expt. 1 in pyrophosphate buffer; $\Delta$, Expt. 2 in pyrophosphate buffer; $O$, Expt. 3 in $\mathrm{Na}_{2} \mathrm{CO}_{3}-\mathrm{NaHCO}_{3}$ buffer. study of this factor was not undertaken as it was uncertain what proportion of GSH remained in the reduced form during the experiments. No activity was observed when GSH was replaced by the same concentration of GSSG, cysteine or acetylcysteine. The absorption spectra of the GSH, cysteine and acetylcysteine derivatives of 3:4-dichloronitrobenzene are all very similar (cf. Bray et al. 1959b), so that if any reaction had taken place a change in $E$ at $344 \mathrm{~m} \mu$ would have been apparent. This confirms the results obtained with paper chromatography, in which GSH was the only one of these three SH compounds which was converted into a derivative of 3:4-dichloronitrobenzene by the soluble liver fraction.

Investigations on the effect of 3:4-dichloronitrobenzene concentration were restricted by the solubility (1 mM) of this substrate, and it was not possible to saturate the enzyme. However, the effect of various substrate concentrations below this value are shown in Fig. 4 in the form of a Lineweaver \& Burk (1934) plot, and the $K_{m}$ calculated from these values was $2.5 \mathrm{mM}\left(2.5 \times 10^{-3} \mathrm{M}\right)$. The inhibition of $S$-(2-chloro-4-nitrophenyl)glutathione formation by other compounds which were

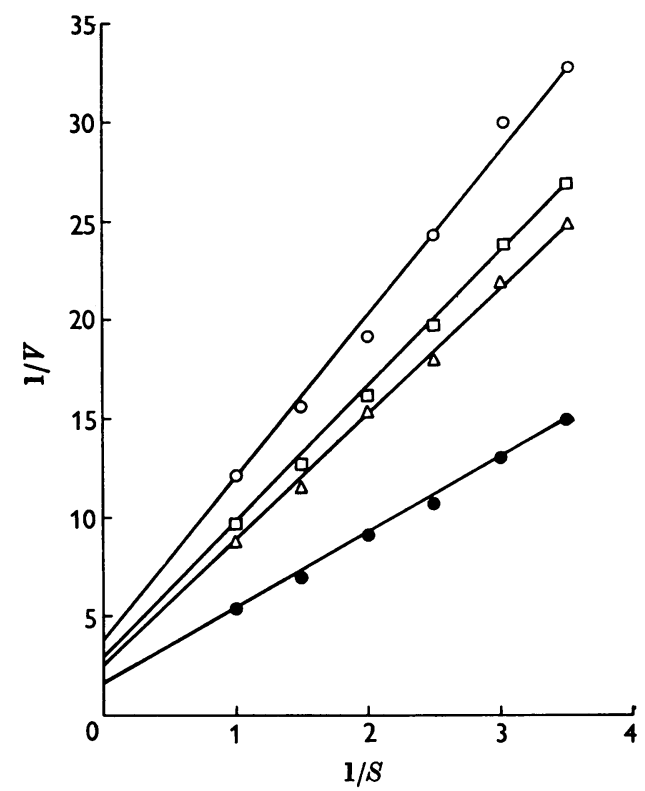

Fig. 4. Effect of benzyl chloride and 1:2-epoxy-1:2:3:4tetrahydronaphthalene on the rate of $S$-(2-chloro-4nitrophenyl)glutathione formation. $S$, 3:4-Dichloronitrobenzene concn. (mM); $V$, initial rate of formation of $S$-(2chloro-4-nitrophenyl)glutathione ( $\mu \mathrm{moles} / \mathrm{ml}$./min.). Reaction mixtures contain 3:4-dichloronitrobenzene, GSH ( $5 \mathrm{mM}$ ) and $0.25 \mathrm{ml}$. of enzyme solution in $3 \mathrm{ml}$. of $0.1 \mathrm{M}$ pyrophosphate buffer, $\mathrm{pH} 8 \cdot 0$, with the following additions: 0 , none; $\triangle, 0.3 \mathrm{~mm}$ - and $O 0.6 \mathrm{~mm}-1: 2-e p 0 x y-1: 2: 3: 4-$ tetrahydronaphthalene; $\square, \mathbf{0 . 6} \mathbf{m m}$-benzyl chloride. 
shown by paper chromatography to form GSH derivatives is also shown in Fig. 4. At all the 3:4dichloronitrobenzene concentrations studied, i.e. $1,0.67,0.5,0.4,0.33$ and $0.285 \mathrm{~mm}$, the addition of 0.6 and 0.3 mM-1:2-epoxy-1:2:3:4-tetrahydronaphthalene caused 55 and $40 \%$ inhibition respectively, whereas at the same concentrations of 3:4-dichloronitrobenzene, $0.6 \mathrm{~mm}$-benzyl chloride caused $44 \%$ inhibition. Furthermore, when the concentration of 3:4-dichloronitrobenzene was kept constant at $1 \mathrm{mM}$, the addition of $0.2,0.4,0.6,0.8$ and 1 mm-benzyl chloride produced 17, 33, 43, 58 and $68 \%$ inhibition respectively. Therefore, regarding 3:4-dichloronitrobenzene as the substrate and the other two compounds as inhibitors, the inhibition is of a non-competitive nature since it is independent of substrate concentration but dependent on inhibitor concentration.

The addition of the following compounds at a final concentration of $1 \mathrm{~mm}$ had no effect on the initial reaction rate: $\mathrm{TPNH}_{2}, \mathrm{DPNH}_{2}, \mathrm{TPN}, \mathrm{DPN}$, flavin mononucleotide, ATP and $\mathrm{MgSO}_{4}$, ascorbic acid, cysteine, acetylcysteine, ethylenediaminetetra-acetate, $\mathrm{KCN}, \mathrm{NaF}, \mathrm{ZnSO}_{4}$ and $\mathrm{MgCl}_{2}$.

Formation of glutathione conjugates with various substrates. The formation of the GSH conjugates was demonstrated by the appearance of ninhydrinpositive spots when the substrates, GSH and soluble liver fraction were incubated in $0.1 \mathrm{M}$ pyrophosphate buffer, pH 8.0. With some substrates a GSH conjugate could be detected only when fresh soluble liver fraction was present in the incubation mixture, indicating that these reactions had been brought about by an enzyme in the liver fraction. Other substrates formed a GSH conjugate in the presence of boiled liver fraction, but a greater amount of the same derivative, as determined by the difference in extinction at $510 \mathrm{~m} \mu$ after reaction with ninhydrin and $\mathrm{Cu}\left(\mathrm{NO}_{3}\right)_{2}$, when the liver fraction was fresh. It was assumed that in these cases both chemical and enzymic reactions had occurred. In no case, however, was the new ninhydrin-positive compound formed if either the substrate or GSH was omitted. The difference in extinctions observed between the two experiments with the same substrate ranged from a three- to a ten-fold increase. However, they could serve only to indicate that an enzymic as well as a chemical reaction had taken place, since a kinetic study with each substrate and the synthesis or isolation of the corresponding GSH derivative would be needed to put them on a quantitative basis. Benzyl chloride, which reacts chemically and enzymically, was used to confirm the specificity of the system for GSH. Paper chromatograms of reaction mixtures in which GSH had been replaced by GSSG showed that no reaction had taken place, and when cysteine or $N$-acetylcysteine replaced the GSH the chemical reaction only was observed. With the substrates iodobenzene, naphthalene, 1-chloronaphthalene and phenanthrene there was no formation of GSH conjugates unless microsomes and $\mathrm{TPNH}_{2}$ were also added. The properties on paper chromatograms of the GSH conjugates detected in these reactions are listed in Table 5.

Naphthalene also yielded a compound which gave a blue colour with reagent 4 and was indistinguishable from trans-1:2-dihydro-1:2-dihydr-

Table 5. Paper chromatography of glutathione conjugates

Solvent systems are as described in Table 1. All conjugates gave pink colours with the ninhydrin-Cu( $\left.\mathrm{NO}_{3}\right)_{2}$ reagent. Type of reaction is indicated by $A$, chemical and $B$, enzymic.

\section{Substrate}

3:4-Dichloronitrobenzene

2:4-Dichloronitrobenzene

2:3:5:6-Tetrachloronitrobenzene

3:4:5:6-Tetrachloro-1:2-epoxycyclohexane

Benzyl chloride

Bromoethane

1.Bromopropane

Ethyl methanesulphonate

Sulphobromophthalein

1:2-Epoxy-1:2:3:4-tetrahydronaphthalene

Iodobenzene*

Naphthalene*

1-Chloronaphthalene*

Phenanthrene*

$\begin{array}{ccc}\overbrace{\text { Solvent (1) }}^{R_{\text {F }} \text { of GSH }} & \begin{array}{c}\text { Solvent (2) } \\ \text { derivative }\end{array} & \begin{array}{c}\text { Type of } \\ \text { reaction } \\ \text { observed }\end{array} \\ 0.45 & 0.62 & \text { B } \\ 0.62 & 0.60 & \text { B } \\ & 0.72 & \text { B } \\ 0.42 & 0.64 & \text { B } \\ 0.50 & 0.67 & \text { A, B } \\ 0.33 & 0.52 & \text { A, B } \\ 0.44 & 0.62 & \text { A, B } \\ 0.33 & 0.52 & \text { A, B } \\ 0.19 & 0.35 & \text { A, B } \\ 0.49 & 0.63 & \text { A, B } \\ 0.40 & 0.56 & \text { B } \\ 0.37 \dagger & 0.47 \dagger & \text { A, B } \\ 0.49 & 0.65 & \text { B } \\ 0.43 \dagger & 0.61 \dagger & \text { B } \\ 0.38 \ddagger & 0.57 \ddagger & \end{array}$

\section{Reference to mercapturic acid excretion in urine}

Bray, James \& Thorpe (1957)

Bray et al. (1957)

Bray, Hybs, James \& Thorpe (1953)

Bray, James \& Thorpe (1958)

Thomson, Maw \& Young (1958)

Grenby \& Young $(1959,1960)$

Roberts \& Warwick (1958)

Boyland \& Sims (1960)

Hele (1924); Mills \& Wood (1953)

Bourne \& Young (1934)

Cornish \& Block (1958)

\footnotetext{
* Required microsomes and $\mathrm{TPNH}_{2}$.

$\dagger$ Gave blue colours with diazotized $p$-nitroaniline and $\mathrm{Na}_{2} \mathrm{CO}_{3}$ (reagent 3).

$\ddagger$ Gave orange colours with reagent (4).
} 
oxynaphthalene on paper chromatograms. Phenanthrene yielded two compounds indistinguishable from trans-1:2-dihydro-1:2-dihydroxy- and trans9:10-dihydro-9:10-dihydroxy-phenanthrene, which gave blue and orange colours respectively on paper chromatograms treated with reagent 4.

\section{DISCUSSION}

The detoxication of foreign compounds, such as the monohalogenobenzenes (Baumann \& Preusse, 1879; Jaffé, 1879), as mercapturic acids has been known for many years, and several GSH compounds have been suggested as the source of the cysteine residues. The possibility that GSH was involved in the detoxication of avertin was suggested by Waelsch (1930). Administration of naphthalene to rabbits caused a decrease in the GSH content of the eye lens and liver (Nakashima, 1934) and Yamamoto (1940) found that when bromobenzene was given to rabbits there was a decrease in the GSH level in several organs, particularly liver, which was paralleled by the amount of $p$-bromophenylmercapturic acid excreted. Bromobenzene, when given to rats, caused an increase in GSH levels in the liver and kidney $30 \mathrm{~min}$. after administration, followed by a decrease in the levels lasting for 2 days, and it was suggested that this decrease was due to the formation of sulphuric acid esters and a mercapturic acid (Binet \& Wellers, 1951). Barnes et al. (1959) gave a variety of mercapturic acid precursors to rats and found falls in the liver GSH level after the administration of the compounds; these falls could be related to the amounts of mercapturic acids formed. One of these compounds was 3:4-dichloronitrobenzene, and it had been shown that rabbits dosed with this substance excreted the mercapturic acid, $N$-acetyl$S$-(2-chloro-4-nitrophenyl)-L-cysteine (Bray et al. 1957). The present work has shown that the biosynthesis of this metabolite can be carried out by tissue preparations in the three stages suggested by Bray et al. $(1959 b)$. The first reaction, which is catalysed by the soluble fraction of rat liver, is the replacement of the para chlorine atom by GSH. Since the activity of the fraction is destroyed by heat and is not affected by dialysis, it appears to be due to an enzyme which has no absolute cofactor requirements. The second stage is the conversion of $S$-(2-chloro-4-nitrophenyl)glutathione into $S$-(2chloro-4-nitrophenyl)-L-cysteine by kidney homogenate, a reaction which is probably due to two enzymes previously found in pig kidney and which catalyse the removal of the glutamyl group from glutathione itself and the hydrolysis of cysteinylglycine (Olson \& Binkley, 1950). That glutathione derivatives can also behave in this way has been shown by the conversion of $S$-( $p$-chlorobenzyl)- glutathione into $S$-( $p$-chlorobenzyl)-L-cysteine by liver slices of various species (Bray et al. 1959a). In the third stage, rat-liver slices were used to demonstrate the $N$-acetylation of $S$-(2-chloro-4-nitrophenyl)-L-cysteine to the mercapturic acid, and again other similar reactions have been reported, such as the $N$-acetylation of $S$-benzyl-DL-homocysteine by rat-liver and -kidney slices (Gutmann \& Wood, 1951) and of $S$-( $p$-chlorobenzyl)-L-cysteine by liver slices (Bray et al. 1959b). The conversion of GSH derivatives into mercapturic acids in vivo has been demonstrated by Roberts \& Warwick (1958), who found that when $S$-ethylglutathione was administered to rats it was excreted as $S$-ethylmercapturic acid, and Stekol $(1940,1941)$ showed that administration of $S$-benzylglutathione and $S$ ( $p$-bromobenzyl)glutathione to rats resulted in the excretion of $N$-acetyl-S-benzyl-L-cysteine and $N$ acetyl-S-( $p$-bromobenzyl)-L-cysteine respectively.

The enzyme catalysing the reaction in which the para chlorine atom of 3:4-dichloronitrobenzene is replaced by GSH appears to be specific for GSH, but not for the other substrate, since it was found that GSH could not be replaced by GSSG, cysteine or $N$-acetylcysteine, whereas other compounds could replace 3:4-dichloronitrobenzene. Many of these are known to be converted into mercapturic acids in the body (see Table 5). With 2:4- and 3:4dichloronitrobenzene (which yield mercapturic acids in which chlorine atoms are replaced by $N$-acetylcysteine), and 2:3:5:6-tetrachloronitrobenzene (which yields a mercapturic acid by the replacement of the nitro group by acetylcysteine), no GSH derivative was obtained if the soluble liver fraction was boiled before the incubation, indicating that these reactions were enzymic. 3:4:5:6Tetrachloro-1:2-epoxycyclohexane also reacted with GSH only in the presence of the soluble liver fraction.

With the substrates bromoethane, 1-bromopropane, benzyl chloride, ethyl methanesulphonate and 1:2-epoxy-1:2:3:4-tetrahydronaphthalene, all of which are alkylating agents, reactions with GSH both in the presence of fresh and of boiled soluble liver fraction was observed although the first reaction was much faster. These reactions were carried out at $\mathrm{pH} 8$, which is the optimum $\mathrm{pH}$ of the enzyme for 3:4-dichloronitrobenzene, so that the observed chemical reaction, presumably requiring ionized SH groups of GSH, is not unexpected. Sulphobromophthalein, which also reacted with GSH both in the presence and the absence of the enzyme, is used as a test substance for liver function because it is removed from the blood by the liver and it is excreted in the bile partly in the form of a GSH conjugate (Javitt, Wheeler, Baker \& Ramos, 1959; Combes \& Stakelum, 1960). It is possible that this liver- 
function test is actually a measure of the activity of the enzyme.

The substrates iodobenzene, naphthalene, 1chloronaphthalene and phenanthrene did not react with GSH in the presence of soluble liver fraction alone, but only if microsomes and $\mathrm{TPNH}_{2}$ were also present. With naphthalene, one of the products thus obtained was indistinguishable on paper chromatograms from $S$-(1:2-dihydro-2-hydroxy-1naphthyl)glutathione, which has been previously identified as a metabolite of naphthalene formed by liver slices (Booth et al. 1960b) and in the bile of rats dosed with naphthalene (Boyland, Ramsey \& Sims, 1961). The second product was trans-1:2dihydro-1:2-dihydroxynaphthalene, which has been reported as a product of the action of microsomes and $\mathrm{TPNH}_{2}$ on naphthalene (Mitoma, Posner, Reitz \& Udenfriend, 1956; Booth \& Boyland, 1957). Phenanthrene gave two GSH conjugates, and also yielded trans-1:2-dihydro-1:2-dihydroxy-and trans9:10-dihydro-9:10-dihydroxy-phenanthrene, which are known metabolites in urine (Boyland \& Wolf, 1950).

When 1:2-dihydronaphthalene is incubated with rat-liver microsomes and $\mathrm{TPNH}_{2}$, perhydroxylation occurs with the formation of trans-1:2:3:4tetrahydro-1:2-dihydroxynaphthalene, whereas if GSH is added $S$-(1:2:3:4-tetrahydro-1-hydroxy-1naphthyl)glutathione is also formed. If rat soluble liver fraction is also present the amounts of the glutathione conjugate formed are much increased (Booth et al. 1960a). It was suggested that in these reactions the action of microsomes and $\mathrm{TPNH}_{2}$ was to convert 1:2-dihydronaphthalene into 1:2-epoxy1:2:3:4-tetrahydronaphthalene, which then reacted with GSH, either with or without the enzyme present in the soluble liver fraction, to yield the GSH conjugate. It seems probable that, in the present work, the four compounds requiring microsomes and $\mathrm{TPNH}_{2}$ in addition to the enzyme are first converted into similar intermediates. With these compounds, however, the presence of the soluble liver fraction is usually necessary for the formation of the GSH conjugates, although occasionally small amounts of the GSH conjugate derived from naphthalene, presumably formed by a chemical reaction with the intermediate, have been detected in experiments in which boiled soluble liver fraction has been used.

Fig. 4 shows in effect that compounds which are apparently alternative substrates for the enzyme inhibit the reaction of GSH with 3:4-dichloronitrobenzene non-competitively. This indicates that these compounds are combining with the enzyme at a point other than the active centre for 3:4-dichloronitrobenzene and would seem to imply that the enzymic reactions involved are different so far as active centres are concerned. It seems likely that the enzyme involved in these reactions can produce an activated form of GSH which then reacts more readily with certain compounds. However, since the dialysed soluble liver fraction was used to catalyse the enzymic reactions shown in Table 5, the possibility that all these GSH conjugates are not formed by the same enzyme is not completely eliminated.

\section{SUMMARY}

1. An enzyme which catalyses the formation of S-(2-chloro-4-nitrophenyl)glutathione from 3:4-dichloronitrobenzene has been partially purified from the soluble fraction of rat liver.

2. S-(2-Chloro-4-nitrophenyl)glutathione is converted into $S$-(2-chloro-4-nitrophenyl)-L-cysteine by rat-kidney homogenate, and this compound can be acetylated to the mercapturic acid, $N$-acetyl$S$-(2-chloro-4-nitrophenyl)-L-cysteine by rat-liver slices.

3. The soluble liver fraction can catalyse the formation of glutathione conjugates from a number of other mercapturic acid precursors.

4. With bromobenzene, naphthalene, 1-chloronaphthalene and phenanthrene, rat-liver microsomes and reduced triphosphopyridine nucleotide as well as the soluble liver fraction are necessary in the formation of the glutathione conjugates.

5. Glutathione cannot be replaced by oxidized glutathione, cysteine or $N$-acetylcysteine in these systems.

This investigation has been supported by grants to the Chester Beatty Research Institute (Institute of Cancer Research: Royal Cancer Hospital) from the Medical Research Council, the British Empire Cancer Campaign, the Jane Coffin Childs Memorial Fund for Medical Research, the Anna Fuller Fund and the National Cancer Institute of the National Institutes of Health, U.S. Public Health Service.

\section{REFERENCES}

Barnes, M. M., James, S. P. \& Wood, P. B. (1959). Biochem. $J .71,680$.

Baumann, E. \& Preusse, C. (1879). Ber.dtsch.chem. Ges. 12, 806.

Binet, L. \& Wellers, G. (1951). Bull. Soc. Chim. biol., Paris, 33, 279.

Booth, J. \& Boyland, E. (1957). Biochem. J. 66, 73.

Booth, J., Boyland, E., Sato, T. \& Sims, P. (1960a). Biochem. J. 77, 182.

Booth, J., Boyland, E. \& Sims, P. (1960b). Biochem. J. 74, 117.

Booth, J., Boyland, E. \& Turner, E. E. (1950). J. chem. Soc. p. 1188.

Bourne, M. C. \& Young, L. (1934). Biochem. J. 28, 803.

Boyland, E., Ramsey, G. S. \& Sims, P. (1961). Biochem. J. 78, 376.

Boyland, E. \& Sims, P. (1960). Biochem. J. 77, 175.

Boyland, E. \& Wolf, G. (1950). Biochem. J. 47, 64. 
Bray, H. G., Franklin, T. J. \& James, S. P. (1959a). Biochem. J. 71, 690.

Bray, H. G., Franklin, T. J. \& James, S. P. (1959b). Biochem. J. 73, 465.

Bray, H. G., Hybs, Z., James, S. P. \& Thorpe, W. V. (1953). Biochem. J. 53, 266.

Bray, H. G., James, S. P. \& Thorpe, W. V. (1957). Biochem. J. 65, 483.

Bray, H. G., James, S. P. \& Thorpe, W. V. (1958). Biochem. $J .70,570$.

Combes, B. \& Stakelum, G. S. (1960). J. clin. Invest. 39, 1214.

Cornish, H. H. \& Block, W.D.(1958). J.biol.Chem. $231,583$.

Fincham, J. R. S. (1954). J. gen. Microbiol. 11, 236.

Grenby, T. H. \& Young, L. (1959). Biochem. J. 71, 25 P.

Grenby, T. H. \& Young, L. (1960). Biochem. J. 75, 28.

Gutmann, H. R. \& Wood, J. L. (1951). J. biol. Chem. 189, 473.

Hele, T. S. (1924). Biochem. J. 18, 586.

Jaffé, M. (1879). Ber. dtsch. chem. Ges. 12, 1092.

Javitt, N. B., Wheeler, H. O., Baker, K. J. \& Ramos, 0. (1959). J. clin. Invest. 38, 1015.

Knight, R. H. \& Young, L. (1958). Biochem. J. 70, 111.

Lineweaver, H. \& Burk, D. (1934). J. Amer. chem. Soc. 56, 658.
Mills, G. C. \& Wood, J. L. (1953). J. biol. Chem. 204, 547. Mitoma, C., Posner, H. S., Reitz, H. C. \& Udenfriend, S. (1956). Arch. Biochem. Biophys. 61, 431.

Nakashima, T. (1934). J. Biochem., Tokyo, 19, 281.

Olson, C. K. \& Binkley, F. (1950). J. biol. Chem. 186, 731.

Parke, D. V. \& Williams, R. T. (1951). Biochem. J. 48, 624

Pirie, N. W. \& Hele, T. S. (1933). Biochem. J. 27, 1716.

Potter, V. R. \& Elvehjem, C. A. (1936). J. biol. Chem. 114, 4951.

Roberts, J. J. \& Warwick, G. P. (1958). Biochem. Pharmacol. 1, 60.

Schneider, W. C. \& Hogeboom, G. H. (1950). J. biol. chem. $183,123$.

Stekol, J. A. (1940). Proc. Soc. exp. Biol., N.Y., 43, 108.

Stekol, J. A. (1941). J. biol. Chem. 138, 225.

Suter, F. (1895). Hoppe-Seyl. Z. 20, 562.

Thomson, E. A. R., Maw, G. A. \& Young, L. (1958). Biochem. J. 69, 23 P.

Umbreit, W. W., Burris, R. H. \& Stauffer, J. F. (1949). In Manometric Techniques and Tissue Metabolism, 2nd ed., p. 119. Minneapolis: Burgess Publishing Co.

Waelsch, H. (1930). Arch. exp. Path. Pharmak. 156, 356.

Warburg, O. \& Christian, W. (1941). Biochem. Z. 310, 384.

Yamamoto, K. (1940). Mitt. med. Akad. Kioto, 29, 431. Cited in Chem. Abstr. (1941) 35, 4484.

Biochem. J. (1961) 79, 524

\title{
The Intrinsic Viscosity of Myosin and the Interpretation of its Hydrodynamic Properties
}

\author{
By P. JOHNSON AND A. J. ROWE \\ Department of Colloid Science, University of Cambridge
}

(Received 14 November 1960)

Early work suggested a particle weight of about 800000 for the myosin molecule, with an axial ratio $(J)$ of 100:1 (Portzehl, 1950), but more recently it has appeared that some of the data employed were in error. For the sedimentation coefficient, a detailed account has been given of the probable cause of this error in terms of moleculartransformation reactions occurring during the experiments (Johnson \& Rowe, 1960). There may well have been similar errors in much recent as well as early diffusion work; also in viscosity, lightscattering and osmotic-pressure experiments. There has as yet, however, been no general agreement upon revised estimates of the size and shape of the myosin molecule.

For the complete definition of an ellipsoid of revolution hydrodynamically equivalent to the myosin molecule, three independent (usually kinetic) parameters must be known, together with the partial specific volume $(\vec{v})$. The method of Scheraga \& Mandelkern (1953) then provides a convenient means for the calculation of the axial ratio and the effective volume/g. $(V)$ of this ellipsoid. Let us take the extrapolated sedimentation and diffusion coefficients, $\left[S_{20}^{0}\right]$ and $\left[D_{20}^{0}\right]$, and the intrinsic viscosity, $[\eta]$, as the three kinetic parameters. $\left[S_{20}^{0}\right]$ has been accurately determined under conditions where myosin is known to be stable (Holtzer \& Lowey, 1956, 1959; Johnson \& Rowe, 1960), as also has $\left[D_{20}^{0}\right]$ (Parrish \& Mommaerts, 1954), although the value given by Parrish \& Mommaerts should be confirmed by an independent and equally thorough study. But the values given in the literature for $[\eta]$ show a surprising degree of scatter, the following being among those reported (dl./g.): $2 \cdot 2$ (Mommaerts, 1945, and Weber, $1950 a, b$ ); 1.8-2.0 (Weber \& Portzehl, 1951; Portzehl, Schramm \& Weber, 1951); 2.3, 2.2 and 2.4 (Holtzer \& Lowey, 1956). Since the completion of this work Holtzer \& Lowey (1959) have reported a value of $2 \cdot 17$ at $25^{\circ}$, and a rather higher value $(2 \cdot 24)$ at $0.7^{\circ}$. In view of the occur- 